\title{
A utilização da prosódia na produção de sentido
}

\author{
Ana Paula Cristina da SILVA (1) \\ Universidade Federal de Juiz de Fora (UFJF)
}

\section{RESUMO}

Durante a apresentação, Anne Wichmann explica como a prosódia pode ser utilizada para atribuir significado pragmático às elocuções, dar estrutura ao texto lido em voz alta, negociar as tomadas de turno, demonstrar um conjunto de emoções e exibir estilos de fala marcados. Por conseguinte, a prosódia pode ser empregada pelo falante para conferir um significado diferente às elocuções, que são sintaticamente semelhantes, entretanto são pragmaticamente diferentes por conta da entonação. Também pode ser usada pelo leitor para marcar as partes estruturais do texto, como título, subtítulo e parágrafo. Além disso, a prosódia pode ser empregada para negociar as tomadas de turno entre falante e ouvinte, demonstrar emoções e apresentar estilos de fala marcados, tais como os estilos de leitura de notícias, contação de estórias/audiobook, liturgia e recitação de poesia.

OPEN ACCESS

EDITADO POR

Raquel Freitag

REVISADO POR

Bruno Rocha

DATAS

Recebido: 14/05/2020

Aceito: 02/06/2020

Publicado: 29/06/2020

COMO CITAR

Silva, A. P. C. (2020).

A utilização da prosódia na produção de sentido. Revista da Abralin, v. 19, n. 2, p. 1-4, 2020

\section{ABSTRACT}

During the presentation, Anne Wichmann explains how prosody can be used to attribute pragmatic meaning to utterances, give structure to the text read aloud, negotiate turn-taking, demonstrate a set of emotions, and display marked speech styles. Therefore, prosody can be employed by the speaker to give a different meaning to the utterances, which are syntactically similar, but are pragmatically different because of the intonation. It can also be used by the reader to mark the structural parts of the text as title, subtitle, and paragraph. Besides, prosody can be employed to negotiate turn-taking between speaker and listener, demonstrate emotions and present marked speech styles, such as the following reading styles: news, storytelling/audiobook, liturgy, and poetry recitation. 


\section{REVISTA DA ABRALIN}

PALAVRAS-CHAVE

Pragmática. Prosódia. Leitura.

\section{KEYWORDS}

Pragmatics. Prosody. Reading.

Anne Wichmann é uma professora emérita da UCLAN (Universidade de Lancashire Central) no Reino Unido. Sua pesquisa é sobre linguagem e fala. Mais especificamente, entonação, prosódia, pragmática e discurso. Em 11 de maio de 2020, a Abralin ao Vivo transmitiu a apresentação da pesquisadora, que recebeu o nome de "Aspects of intonation meaning: what do our voices convey?" sobre como a entonação contribui para a expressão do significado além das palavras empregadas pelos indivíduos. A palestra foi dividida em seções que compreendem significado pragmático, estrutura do texto, tomada de turno, emoções e estilos de fala.

A professora inicia a apresentação explicando que a prosódia tem vários componentes como ritmo, volume, qualidade da voz e tom. Enquanto alguns pesquisadores usam a palavra entonação para se referir à prosódia, Wichmann afirma que a usa apenas se referindo ao tom. Após as explicações introdutórias, as seções são apresentadas. A primeira foi intitulada significado pragmático, que pode ser entendido como o sentido obtido a partir do contexto extralinguístico de uma elocução. Esse fenômeno permeia técnicas como os atos de fala e a polidez. Alguns exemplos foram empregados pela palestrante a fim de lidar com este tema. Um deles foi a pergunta: você já ouviu falar sobre o acidente? E as respostas não $(\uparrow)$ e não $(\downarrow)$. A diferença pragmática entre as réplicas depende do tom ascendente da primeira e do tom descendente da segunda. O tom descendente leva o orador a continuar a falar sobre o acidente, dando mais detalhes. Enquanto a segunda resposta - o tom descendente - fecha o tópico, sugerindo que o falante não deve contar mais ao ouvinte sobre o fato.

Na seção chamada estrutura do texto, ocorre uma discussão sobre a forma como os leitores fornecem informações enquanto estão lendo em voz alta. Quando as pessoas têm um texto em mãos, elas podem ver estruturas, tais como títulos, subtítulos, parágrafos e colunas, mas quando estão apenas ouvindo alguém o ler, precisam reconhecê-las. Assim, os leitores enfatizam palavras, usando tom mais alto ou não as destacam, utilizando tom mais baixo, levantam a tonalidade para indicar que estão começando um novo tópico e empregam entonação descendente quando estão lendo o título.

Considerando que a tomada de turnos acontece suavemente em inglês, com poucas sobreposições entre os indivíduos, o falante conclui que deve utilizar estratégias (que englobam sinais prosódicos e/ou não verbais) para sinalizar ao interlocutor que ele deseja manter ou finalizar seu turno de fala. Consequentemente, ao perceber essas estratégias, o interlocutor sabe que pode começar um turno, mesmo que o falante não tenha feito uma longa pausa. O ouvinte sente o tom cair e uma pequena pausa, então compreende que pode tomar o turno. Outros sinais também podem indicar que a fala pode ser tomada como, por exemplo, o olhar, movimentos de cabeça e de mão. Em alguns ambientes de tomada 


\section{REVISTA DA ABRALIN}

de turno, existem duas práticas muito empregadas: rush-through e backchannels. Rush-through é uma técnica utilizada para segurar o turno ao acelerar o passo da conversa e backchannels são feedbacks que os falantes precisam durante o diálogo para mostrar que os ouvintes ainda estão os escutando como, por exemplo, aham, certo, uhum, mmm, sim e entendo. No rush-through, as pessoas querem segurar o turno e mesmo quando estão chegando a uma conclusão do tema, desejam começar outro. Em vez de alcançar um tom baixo final, aceleram o que estão dizendo para iniciar o novo tópico sem serem interrompidas pelo ouvinte. Nos backchannels, os ouvintes usam entonação ascendente (aham $\uparrow$ ), indicando o desejo de que o falante continue ou utilizam entonação descendente (aham $\downarrow$ ) para demonstrar a vontade de que ele os entregue o turno. De acordo com a professora, rush-through e backchannel são usados eminentemente em entrevistas por políticos.

No tópico sobre emoções, acontece uma discussão sobre a complexidade da pesquisa, haja vista que quando o pesquisador pergunta a emoção expressa por uma entonação a diferentes entrevistados, eles podem dar rótulos distintos (por exemplo: triste, sombrio, miserável). Portanto, seria difícil agrupá-los e ter um rótulo evidente para uma emoção particular. Outra dificuldade é obter os dados de forma ética, considerando que não é ético fazer as pessoas sentirem uma emoção ruim ou boa apenas por causa da pesquisa. Para lidar com esses problemas, alguns pesquisadores utilizam atores durante o estudo. Embora possa parecer um pouco artificial, não é antiético e mesmo com dados reais gravados, o estudioso não poderia garantir que o pesquisado está de fato sentindo tal emoção, porque as pessoas nem sempre mostram os seus sentimentos verdadeiros. Em seguida, a palestrante propõe um conjunto de emoções, a saber: alta energia e expressão muito ativa de emoções, neutra e energia muito baixa. Em alta energia e expressão muito ativa de emoções - boas ou ruins - as pessoas usam uma gama ampla de tom. Em neutra, os indivíduos são mais impessoais (nem negativos, nem positivos). Em energia muito baixa, elas podem expressar emoções passivas (por exemplo: depressão, felicidade serena) com muito pouca energia e alcance restrito de tom.

A última parte da palestra foi sobre estilos de fala, que são definidos como formas de falar de acordo com o contexto em que a pessoa se encontra. Citando o livro de David Crystal Investigating English Style como uma obra que trata desse tema, Anne Wichmann explica que o linguista escreveu sobre estilos de leitura marcados, como comentários esportivos e estilo litúrgico. Wichmann está particularmente interessada no conjunto de entonações de quatro estilos de leitura marcados retratados por Crystal: as notícias, contação de estórias/audiobook, liturgia e recitação de poesia. Em vista disso, a leitura de notícias é feita de forma mais impessoal. O ouvinte não espera expressões de emoções do leitor. A voz é usada somente para transmitir a informação. A contação/audiobook é muito diferente da leitura de notícias, pois se espera que o leitor seja expressivo e crie experiências para o ouvinte. O leitor deve evocar as emoções envolvidas na estória, criando suspense, dando ênfase, imitando as vozes dos personagens, parando ou acelerando a leitura. Além de também possuir o encargo de dar um senso de estrutura textual aos ouvintes (por exemplo: títulos, parágrafos, novos tópicos). Na liturgia, o indivíduo emprega um tom mais restrito, às vezes semelhante ao canto, pequenas frases e seções como saudações, leitura da Bíblia, sermão e avisos. Já a recitação de poesia é semelhante à liturgia (poesia lírica) e à narrativa (poesia narrativa) e tem ênfase adicional no ritmo. Usando a perspectiva de Goffman 


\section{REVISTA DA ABRALIN}

(Presentation of Self e Forms of talk), Wichmann reformula a análise para ver quanto do self do leitor está implícito na leitura e quem é o ouvinte. Nesse aspecto, as pessoas podem ler como: i. autor; ii. intérprete ou iii. porta-voz e podem ouvir como i. destinatário ou ii. testemunha. Sendo assim, o leitor de notícias é um porta-voz e os ouvintes não são vistos pelo profissional, entretanto cada um deles pensa estar sendo endereçado. O contador de estórias é o intérprete do texto. Está envolvido com a narrativa, anima a voz dos personagens e transmite a estrutura textual. O ouvinte deve ser atraído pela estória e cumpre o papel de endereçado. O declamador de poesia narrativa é um intérprete, que simula a voz e as emoções do eu lírico e o ouvinte é o destinatário do poema. Já o recitante de poesia lírica é um porta-voz - um instrumento transmissor do texto - que está pensando ou refletindo em voz alta e o ouvinte é visto como testemunha da reflexão. Por fim, o executante da liturgia é um porta-voz e o ouvinte (a congregação) é a testemunha do evento.

Dado o exposto, a apresentação de Ann Wichmann foi de grande valor, pois englobou um tema importante para as teorias da Pragmática e do Discurso, os significados por trás da entonação. A professora foi muito didática nas suas explicações e certamente foi entendida pelo público. Foi muito interessante a forma como ela interagiu com as obras de David Crystal e Ervin Goffman, criando pontes entre o conhecimento deles e o dela. Depois de terminada a palestra, Wichmann respondeu a todas as perguntas feitas durante a live, como havia informado que faria no início do evento. Além disso, este conjunto de palestras transmitido pela Abralin é de grande importância para os linguistas e estudantes em todo o mundo. Haja vista que é uma maneira de manter o ambiente de pesquisa mesmo em um momento tão sombrio como este de COVID-19.

\section{REFERÊNCIAS}

ASPECTS of intonation meaning: what do our voices convey?. Conferência apresentada por Anne Wichmann [s.l., s.n], 2020. 1 vídeo (45min 07s). Publicado pelo canal da Associação Brasileira de Linguística. Disponível em https://www.youtube.com/watch?v=LL5GHTF6nNE\&t=2342s. Acesso em: 11 mai 2020.

CRYSTAL, D.; DAVY, D. Investigating English style. Bloomington: Indiana University Press, 1969.

GOFFMAN, E. Forms of Talk. Philadelphia: University of Pennsylvania Press, 1981.

GOFFMAN. The presentation of self in everyday life. Nova York: Anchor Books, 1959. 